Provided for non-commercial research and educational use only. Not for reproduction or distribution or commercial use.

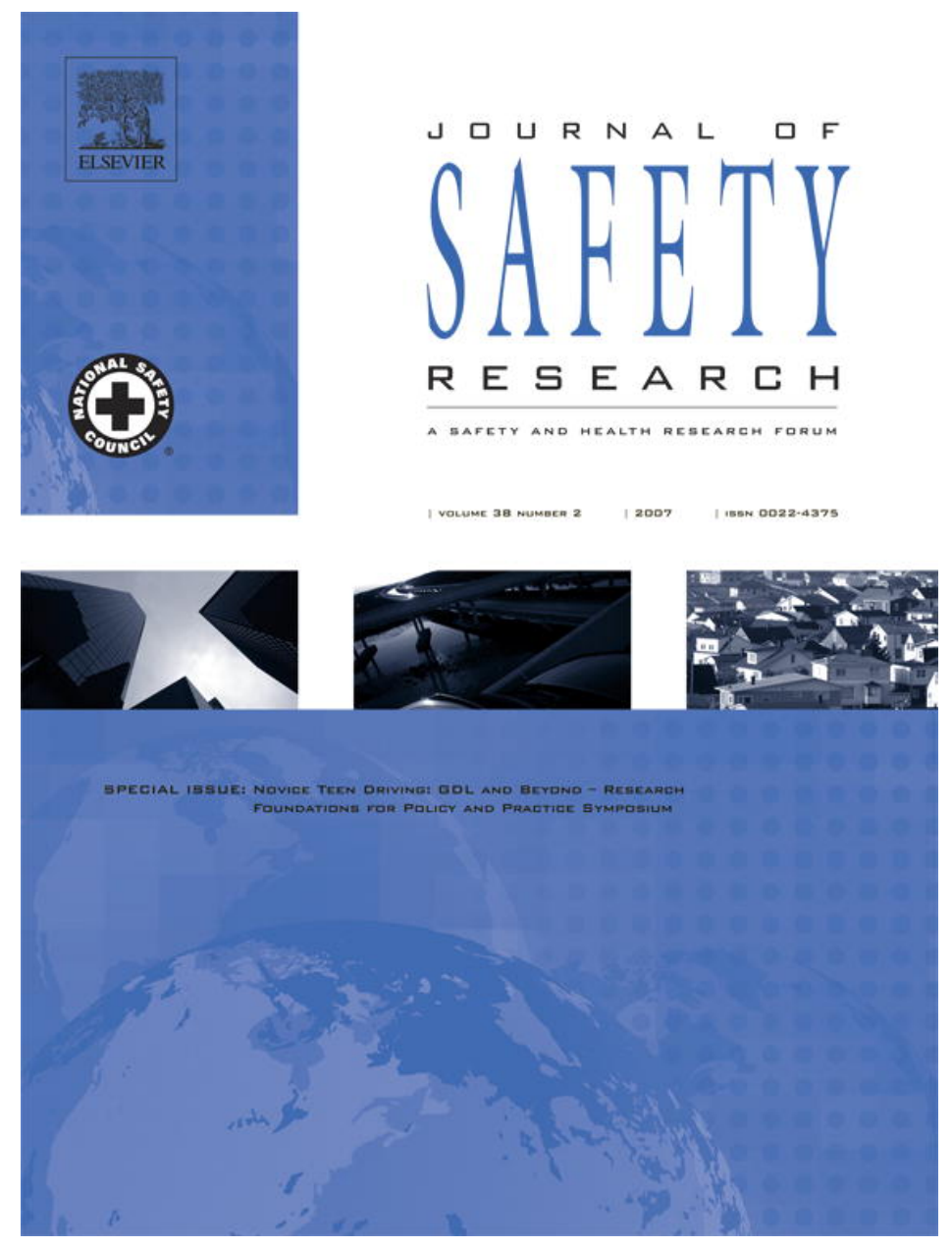

This article was originally published in a journal published by Elsevier, and the attached copy is provided by Elsevier for the author's benefit and for the benefit of the author's institution, for non-commercial research and educational use including without limitation use in instruction at your institution, sending it to specific colleagues that you know, and providing a copy to your institution's administrator.

All other uses, reproduction and distribution, including without limitation commercial reprints, selling or licensing copies or access,

or posting on open internet sites, your personal or institution's website or repository, are prohibited. For exceptions, permission may be sought for such use through Elsevier's permissions site at: 


\title{
Technology and teen drivers
}

\author{
John D. Lee* \\ University of Iowa, Department of Mechanical and Industrial Engineering, 2130 Seamans Center, Iowa City, IA 52242
}

Available online 26 March 2007

\begin{abstract}
The rapid evolution of computing, communication, and sensor technology is likely to affect young drivers more than others. The distraction potential of infotainment technology stresses the same vulnerabilities that already lead young drivers to crash more frequently than other drivers. Cell phones, text messaging, MP3 players, and other nomadic devices all present a threat because young drivers may lack the spare attentional capacity for vehicle control and the ability to anticipate and manage hazards. Moreover, young drivers are likely to be the first and most aggressive users of new technology. Fortunately, emerging technology can also support safe driving. Electronic stability control, collision avoidance systems, intelligent speed adaptation, and vehicle tracking systems can all help mitigate the threats to young drivers. However, technology alone is unlikely to make young drivers safer. One promising approach to tailoring technology to teen drivers is to extend proven methods for enhancing young driver safety. The success of graduated drivers license programs (GDL) and the impressive safety benefit of supervised driving suggest ways of tailoring technology to the needs of young drivers. To anticipate the effects of technology on teen driving it may be useful to draw an analogy between the effects of passengers and the effects of technology. Technology can act as a teen passenger and undermine safety or it can act as an adult passenger and enhance safety. Impact on industry: Rapidly developing technology may have particularly large effects on teen drivers. To maximize the positive effects and minimize the negative effects will require a broad range of industries to work together. Ideally, vehicle manufacturers would work with infotainment providers, insurance companies, and policy makers to craft new technologies so that they accommodate the needs of young drivers. Without such collaboration young drivers will face even greater challenges to their safety as new technologies emerge.
\end{abstract}

(C) 2007 National Safety Council and Elsevier Ltd. All rights reserved.

Keywords: Distraction; young drivers; novice drivers; collision avoidance; graduated licensing

Emerging technology represents a mixed blessing for drivers, particularly young drivers. Young drivers are overrepresented in car crashes and emerging technology has the potential to both exacerbate and mitigate that tendency. New infotainment technologies, such as cell phones, text messaging, and MP3 players have the potential to aggravate the factors that place young drivers at risk in the first place. At the same time, emerging technologies that support the driver, such as electronic stability control, collision warning systems, and intelligent speed adaptation can enhance driving safety and may even mitigate the risks posed by infotainment distractions. Young drivers may benefit most from the new safety systems, but they are also most vulnerable to poorly implemented technology (Dingus

\footnotetext{
* Tel.: +1 319384 0810; fax: +1319 3355669 .

E-mail address: jdlee@engineering.uiowa.edu.
}

et al., 1997; McKnight \& McKnight, 1993). Properly tuned to the needs of young drivers, technology can extend and complement graduated licensing programs.

This paper considers emerging technology in the context of the factors that put young drivers at risk. This perspective identifies how to tailor technology to young drivers and enhance their driving safety. This paper first describes a conceptual model that identifies factors that undermine the safety of young drivers. These factors are then compared to the demands infotainment systems place on drivers to show why these systems pose a particular threat to young drivers. The paper then describes driver support technology that might mitigate distraction and complement the two most effective safety interventions - Graduated Drivers Licensing (GDL) and supervised driving. The paper concludes with a caution that even well-intentioned technology-based solutions are likely to fail if they do not consider interactions with teen 
culture and parental involvement. To anticipate the effects of technology on teen driving it may be useful to consider it as a passenger. Technology can act as a teen passenger and undermine safety or it can act as an adult passenger and enhance safety.

\section{Magnitude and mechanisms of the young driver safety problem}

The overrepresentation of young drivers in car crashes makes driving the leading cause of death for people between the ages of 4 and 34 (Subramanian, 2005). On a per-mile basis, young drivers aged 16 to 19 are overrepresented in severe crashes by a factor of 10 , compared with adult drivers aged 40 to 50 (McKnight \& McKnight, 2003). The crash rate is particularly high in the first six months after licensure (Mayhew, Simpson, \& Pak, 2003). Fig. 1 shows that crash involvement dramatically declines as novice drivers gain experience. It also shows a dramatic difference between learner drivers, who are supervised by an experienced driver, and novice drivers who are not.

The mechanisms that underlie the crashes of young drivers are difficult to isolate and their interactions with new technology are largely unexplored. This difficulty stems, in part, from the natural confounding of age, lifestyle, and experience, but it also stems from the composite nature of the multi-level control task that is driving (Summala, 1996). As an example, the difference between novices and learners in Fig. 1 likely reflects both the restricted exposure to dangerous situations and the aid provided by the adult passenger in identifying hazards and reducing the burden of navigation.

Fig. 2 shows a simple representation of driving as a threelevel control task in which breakdowns at one level propagate to other levels (Allen, Lunenfeld, \& Alexander, 1971; Michon, 1985; Ranney, 1994; Summala, 1996). At the bottom of this figure is operational control of the vehicle, which reflects drivers' ability to maintain a desired speed or lane position. Moving outward from this is the tactical control of the vehicle, which reflects drivers' ability to select an appropriate speed, identify and anticipate hazards, and identify necessary maneuvers. The uppermost loop in Fig. 2 reflects strategic behavior associated with the choice of a destination, route, acceptance of norms and risks, and whether to allow passengers into the car. Failures of control at each level and the subsequent propagation of these failures across levels describes many of the factors that contribute to the overrepresentation of young drivers in car crashes.

Each level of control in Fig. 2 includes a closed loop control system. Driving safety depends on effective feedback and feedforward control at each of these levels. Feedback control depends on the timely assimilation of information regarding how well actions achieve the driver's goals. Feedforward control depends on how well an internal model allows the driver to anticipate future events so that control actions can be planned to meet the driver's goals. Annotations in Fig. 2 highlight some of the reasons for the high crash rate of young drivers, which include:

1. Imperfectly learned vehicle control skills, which lead to poor control and less spare attentional capacity to accommodate unexpected roadway demands (Patten, Kircher, Ostlund, Nilsson, \& Svenson, 2006; Shinar, Meir, \& Ben-Shoham, 1998).

2. Poor ability to anticipate and identify hazards (Fisher, Pollatsek, \& Pradhan, 2006; McKenna, Horswill, \& Alexander, 2006; Pollatsek, Fisher, \& Pradhan, 2006).

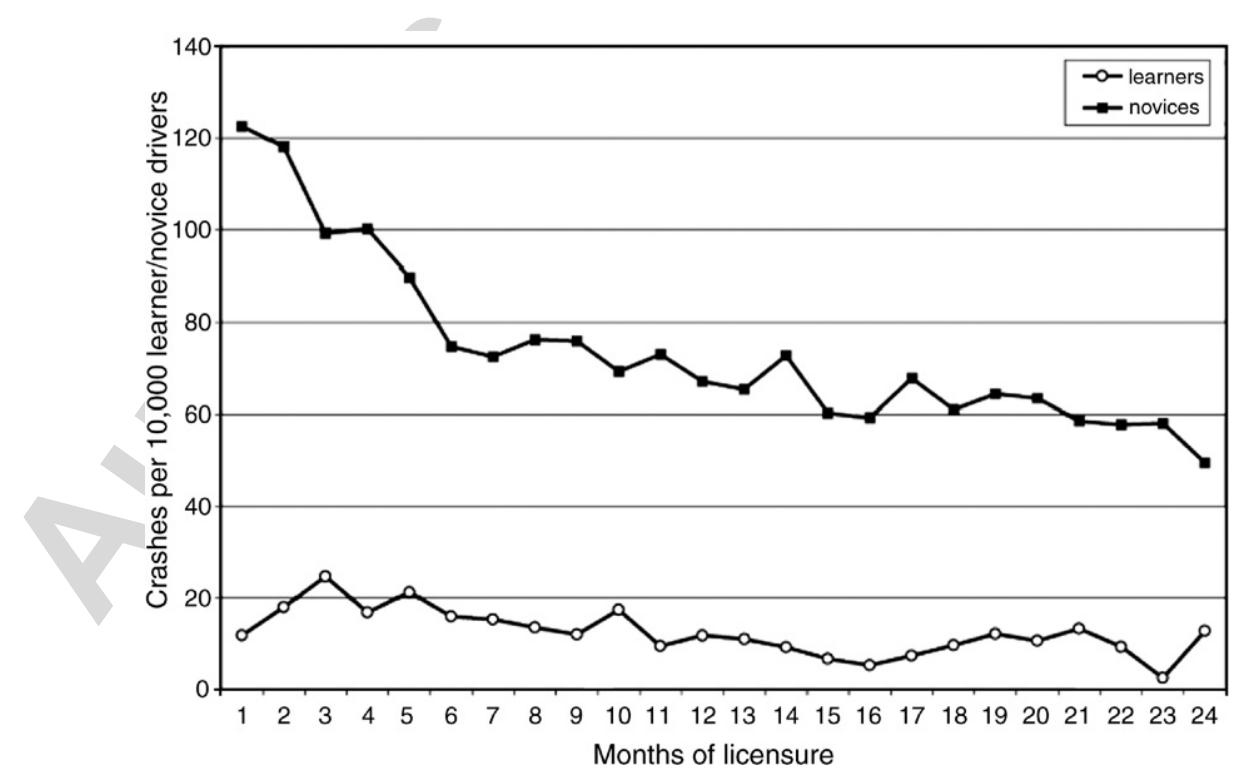

Fig. 1. Crash rates for drivers under the supervision of an adult and during the first months of independent driving. Reprinted from Accident Analysis \& Prevention, 35, Mayhew, D. R., Simpson, H. M., \& Pak, A., Changes in collision rates among novice drivers during the first months of driving, 683-691, 2003, with permission by Elsevier. 


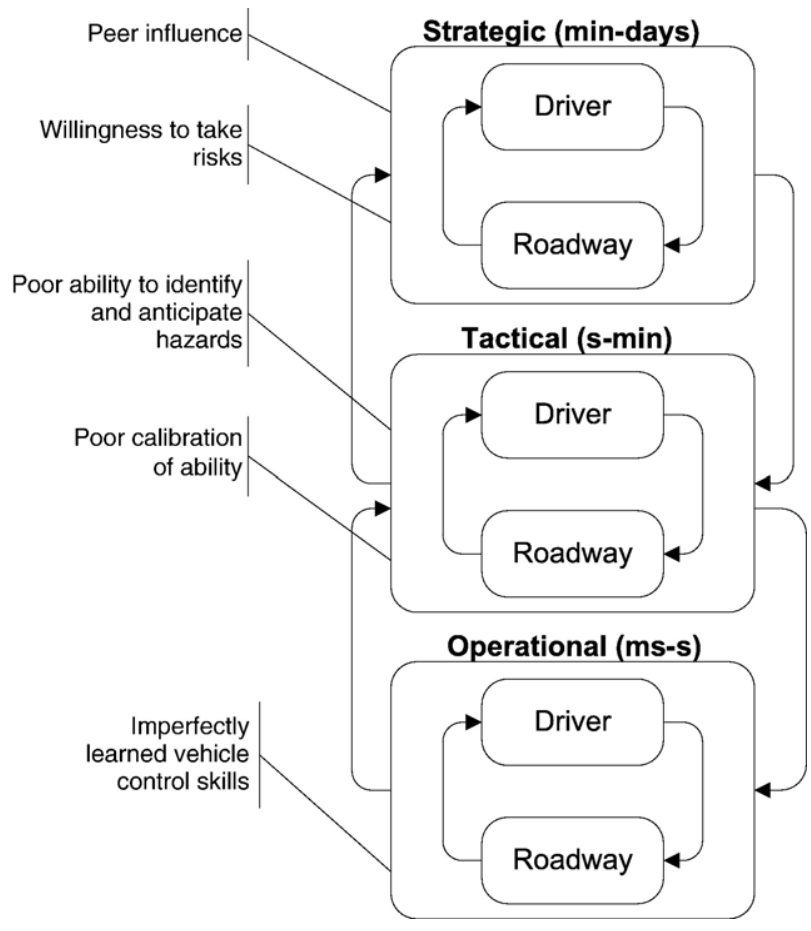

Fig. 2. A multi-level control representation that shows the factors that undermine teen driving safety at each level of control and the cascade effects that operate across levels.

3. Willingness to take risks, such as shorter following distances and higher speeds (Evans \& Wasielewski, 1983; Laapotti, Keskinen, Hatakka, \& Katila, 2001).

4. Poor calibration of abilities relative to driving demands (Horswill, Waylen, \& Tofield, 2004; Ivancic \& Hesketh, 2000; Matthews \& Moran, 1986).

5. Sensitivity to peer influences in adopting inappropriate norms (Lin \& Fearn, 2003; Simons-Morton, Lerner, \& Singer, 2005).

A narrative analysis of 2000 crashes involving 16- to 19year-old drivers provides some concrete examples of breakdowns in this multi-level control process with young drivers (McKnight \& McKnight, 2003). This analysis found that most crashes result from errors of attention, visual search, speed selection, hazard recognition, and control during emergency maneuvers. Others have found that younger drivers are overrepresented in crashes involving excessive speeds, curves, alcohol, fatigue, distraction, and passengers (Ferguson, 2003; Williams, 2003). Overall, the predominant risk factors for younger drivers are lack of skill and poor judgment (McGwin \& Brown, 1999). Lack of skill results in failure of control at the operational level, and poor judgment contributes to breakdowns in the tactical and strategic levels. A breakdown at any of the three levels can undermine driving safety.

The levels of control interact to produce cascade effects that may have particularly powerful consequences for driving safety. Cascade effects occur when the outcome at one level of control affects control at another. As an example, the strategic decision to drive at night places greater demands on a driver's ability to detect hazards, such as sharp curves, at the tactical level. Failures at the tactical level to detect those curves in a timely manner places a high demand on the driver's vehicle control skills at the operational level, and may ultimately lead to a loss of control of the car. Cascade effects can also propagate from the lower loop to the upper loops. For example, preoccupation with vehicle control can cause drivers to neglect hazards. Failing to appreciate the hazards associated with a particular route consequently makes it unlikely a driver will try to avoid that route in the future. The interaction between levels of control reveals the complexity that underlies the combination of factors that contribute to the high crash rates of young drivers.

\subsection{Imperfectly learned control skills}

The first months of unsupervised driving are particularly dangerous. Sixteen-year-old drivers have a crash rate 10 times as great as that of adults but, within the first 500 miles, a two-thirds reduction in their crash rate occurs (McKnight \& McKnight, 2003). Similarly, a month-bymonth analysis of crash rates in young drivers showed a $41 \%$ decline in the first six months and a $60 \%$ decline after two years of driving (Mayhew et al., 2003). This reduction in crash rates partially reflects the development of basic control skills associated with the operational level of driving, shown as the lower loop of Fig. 2. For example, in the first few months of driving, young drivers are overrepresented in fatal rollover crashes that result from a loss of control. This suggests that deficiencies in vehicle control skills leave young drivers unable to accommodate the vehicle control demands of some driving situations.

After the first year of driving, the risk for young drivers is still much greater than for adults. Young drivers may master basic motor skills such as shifting gears, but it may take several years for these skills to become automatized. The attentional demands of these imperfectly learned skills diminish drivers' ability to attend to and manage other driving tasks, such as sign perception (Shinar et al., 1998). Likewise, the longer fixation durations for novices in highdemand situations suggest young drivers are more susceptible to attentional capture (Crundall \& Underwood, 1998). This tendency can be seen in the results of a study that compared experienced and inexperienced drivers' performance on a peripheral detection task. Inexperienced drivers took an average of $250 \mathrm{msec}$ longer to detect peripheral targets, suggesting that such drivers have not automatized many driving skills and lack the spare attentional capacity that enabled experienced drivers to respond quickly to the peripheral targets (Patten et al., 2006). Spare attentional capacity refers to the difference between the cognitive resources demanded by the task and the resources available to invest in the task (Kahneman, 1973). Less spare capacity leads to less proactive hazard management, which in turn 

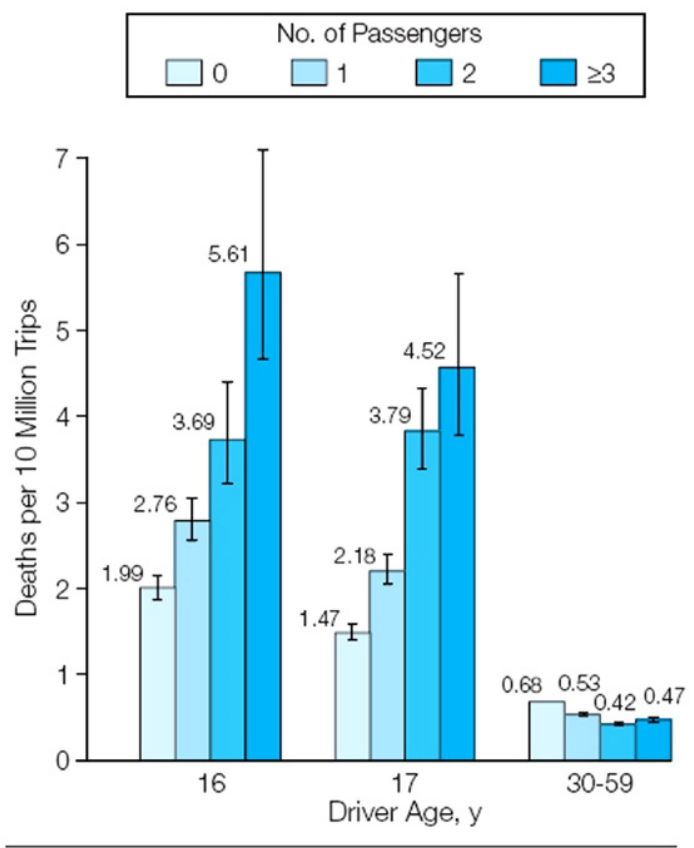

Error bars are $95 \%$ confidence intervals.

Fig. 3. Peer passengers increase the fatality rates of young drivers (Chen, Baker, Braver, \& Li, 2000). Reprinted with permission of the American Medical Association.

exposes young drivers to hazardous situations that place great demands on their imperfect vehicle control skills.

\subsection{Poor hazard awareness}

The lack of spare capacity associated with imperfectly learned vehicle control skills contributes to poor hazard awareness, but does not fully explain the deficiency. Another contributing factor is that young drivers lack the internal model needed to adapt their scanning behavior to detect hazards effectively. Eye movement data show that the visual search of inexperienced drivers is less effective than that of more experienced drivers (Mourant \& Rockwell, 1972). A study of visual search behavior, as measured by fixation duration and horizontal and vertical distribution of gaze, showed that experienced drivers adapt their scanning behavior to reflect the demands of the roadway. In contrast, novice drivers' search strategies lack the flexibility to acclimate to the changing visual demands associated with different roadways (Crundall \& Underwood, 1998). Novice drivers are also less sensitive to how the situation should influence their use of mirrors (Underwood, Crundall, \& Chapman, 2002).

With experience, the scanning behavior of young drivers adjusts to reflect the spatial-temporal characteristics of hazardous situations (Brown \& Groeger, 1988). As an example, drivers' scanning becomes more sensitive to road type with experience (Underwood, Chapman, Brocklehurst, Underwood, \& Crundall, 2003). The response of novice drivers to risky situations in a driving simulator confirms these findings and shows that young drivers lack awareness of risky situations (Fisher et al., 2002; Pollatsek et al., 2006). Novice drivers distribute their attention poorly because they rely on impoverished mental models to support feedforward control and because the demands at the operational level may undermine endogenous control of visual attention.

\subsection{Risk acceptance and capability calibration}

Even if young drivers detect hazards they may underestimate the risk posed by them. Two complementary tendencies may lead younger drivers to choose risky behavior: they tend to overestimate their ability and they tend to accept greater risk. Drivers generally overestimate their abilities. In one study, half the drivers judged themselves to be among the safest $20 \%$, and $88 \%$ believed themselves to be safer than the median driver (Svenson, 1981). Similarly, young drivers rate their ability as greater than that of their peers and that of experienced drivers (Matthews \& Moran, 1986). Such overconfidence is particularly dangerous for younger drivers who may not perceive the hazards that could overwhelm their ability, and so may be doubly impaired in their ability to adapt their behavior to the situation.

Even if young drivers could correctly assess their capability, they still might expose themselves to greater risk. One survey polled young and experienced drivers to assess risky driving behavior, such as drinking and driving, failure to use seat-belts, and violations and crashes (Jonah, 1990). Young drivers were more likely to engage in risky driving and to have higher crash and violation rates. This effect was greater for males than females. Risky driving, violations, and crash involvement were all positively correlated (Jonah, 1990). Similarly, factors such as few parental restrictions and low grade point average were associated with higher crash risk and more violations (McCartt, Shabanova, \& Leaf, 2003). Risk taking can be particularly problematic because it may lead young drivers into situations that overwhelm their vehicle control skills.

\subsection{Peer influences and behavioral norms}

Passengers generally have a protective effect on experienced drivers; people tend to drive more safely when passengers are present. Fig. 3 shows the protective effect is reversed with younger drivers carrying passengers of the same age (Vollrath, Meilinger, \& Kruger, 2002). Passengers of the same age dramatically undermine the safety of young drivers (Lin \& Fearn, 2003; Williams, 2003). Teen passengers have such a detrimental effect because they can influence the driver at all levels of control, from distracting them from the driving task to inducing greater risk taking behavior. As an example, young male passengers led both male and female teen drivers to drive faster (Simons-Morton et al., 2005). Both inside and outside the vehicle, peers influence the norms that guide young drivers' behavior. 
Peer norms and risky behavior, inappropriate confidence, and poor awareness for hazards, all lead young drivers into situations where their underdeveloped skills leave insufficient capacity for controlling demanding situations. In many ways inexperienced drivers may respond to infotainment technology as if it were a teen passenger. As a consequence, infortainment technology exacerbates all of the risk factors that undermine the safety of young drivers.

\section{Infotainment technology trends and the vulnerabilities of young drivers}

Infotainment systems include a broad array of devices that enable drivers to perform tasks unrelated to driving, such as making telephone calls, watching videos, managing e-mail, sending and reading instant messages, and selecting and listening to music. Even relatively mundane infotainment devices, such as the car radio, are changing substantially with the introduction of satellite radio and MP3 music players, like the iPod. As of 2007 , approximately $70 \%$ of new cars will include the capability to connect to iPods.

All of these systems have the potential to distract drivers, but cell phones have attracted the most attention. New services made possible by Wireless Applications Protocol (WAP) may be even more distracting. Text messaging represents one such service that already poses a substantial distraction. One Australian study reported that $30 \%$ of people surveyed had used text messaging while driving and that $16 \%$ regularly used text messaging while driving (Telstra, 2003). Not only are infotainment devices becoming increasingly available, but their use in cars is increasing. For example, the percentage of drivers who were talking on a cell phone at any given moment during daylight hours has increased from 3\% in 2000 to $8 \%$ in 2004 (Glassbrenner, 2005). A similar pattern can be expected with emerging technology, such as text messaging systems.

A growing number of distractions are also emerging on the roadway. Static billboards are giving way to digital billboards that are able to display animated images. Such images attract visual attention much more effectively than static images, sometimes attracting glances in unsafe situations, such as during periods of short headways (Smiley, Smahel, \& Eizenman, 2004).

Distraction is a substantial safety problem. Between $13 \%$ and $50 \%$ of all crashes are attributed to driver distraction or inattention (Stutts, Reinfurt, Staplin, \& Rodgman, 2001; Sussman, Bishop, Madnick, \& Walter, 1985; Wang, Knipling, \& Goodman, 1996). By one estimate, cell phone distractions contribute to a yearly cost of 2,600 fatalities, 330,000 injuries, and a total societal cost of $\$ 43$ billion (Cohen \& Graham, 2003). The demands of cell phone conversations and their contribution to driver distraction are well documented (Horrey \& Wickens, 2006; Lee \& Strayer, 2004; McCartt, Hellinga, \& Bratiman, 2006). Although less is known about emerging infotainment technologies, many pose a threat to driving safety that is at least as great as cell phones (Regan, Lee, \& Young, in preparation).

Fig. 4 shows that infotainment technology diminishes driving safety by undermining the operational, tactical, and strategic levels of control. A high rate of early adoption of new technology, peer pressure, risk-taking tendencies, poor ability to detect and anticipate hazardous situations, and

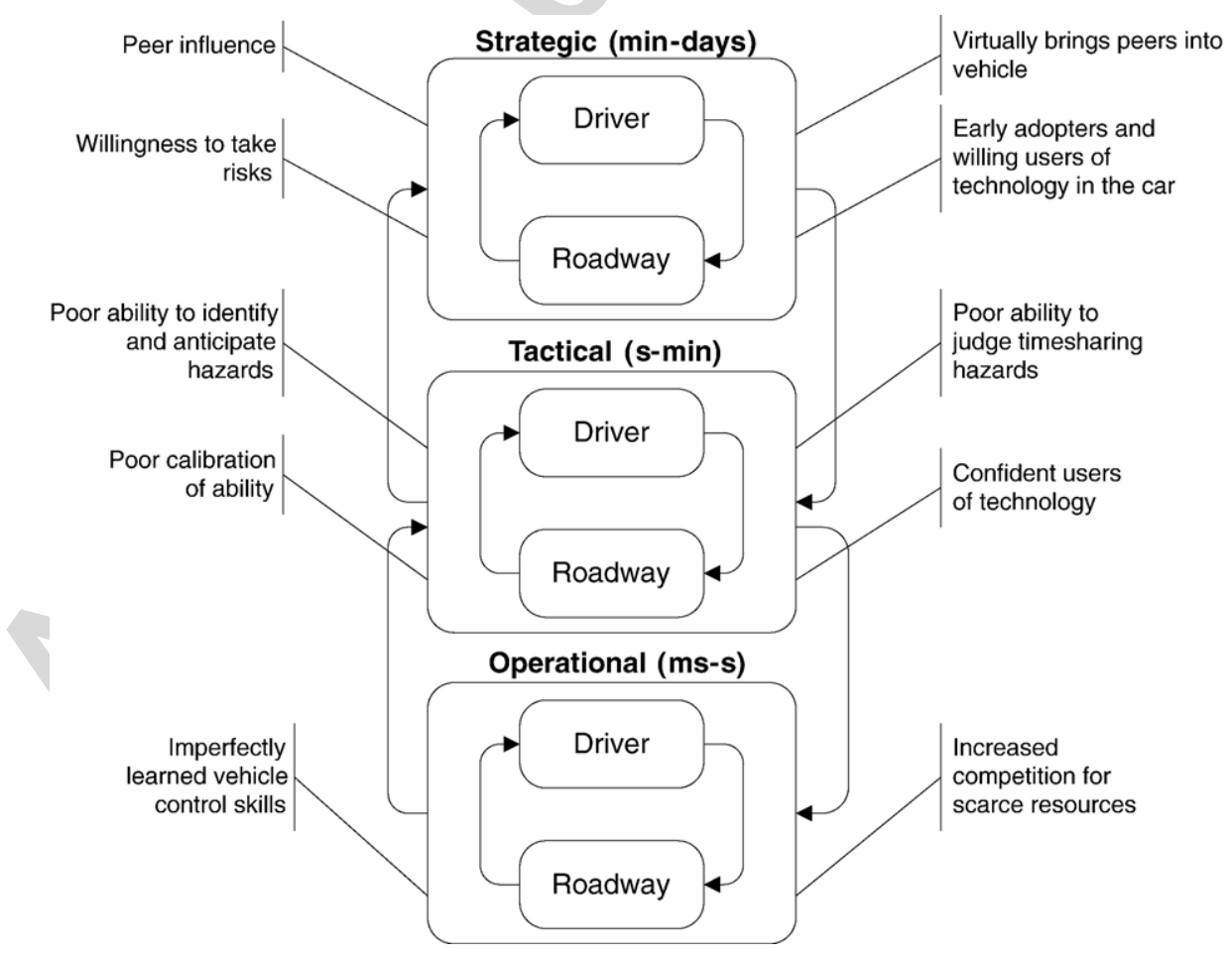

Fig. 4. Infotainment technology stresses existing factors that undermine young driver safety. 
underdeveloped vehicle control skills all leave young drivers particularly vulnerable to the distractions posed by the increasing variety of infotainment systems. As with the general factors that undermine the safety of young drivers, cascade effects can amplify the safety consequences of technology.

\subsection{Resource competition and conflicts in vehicle control}

Using an infotainment system can easily interfere with vehicle control at the operational level. Not surprisingly, drivers' ability to keep the car in the lane and respond to braking lead vehicles diminishes when they look away from the road (Lamble, Laakso, \& Summala, 1999; Senders, Kristofferson, Levison, Dietrich, \& Ward, 1967). Even when the infotainment interaction does not involve looking away from the road, as in a conversation with a handsfree cell phone, it increases the reaction time to events such as a braking lead vehicle by approximately $300 \mathrm{~ms}$ (Alm \& Nilsson, 1994, 1995; Horrey \& Wickens, 2006). Phone conversations also degrade perceptual judgments (Brown, Tickner, \& Simmonds, 1969).

Interactions with infotainment systems diminish drivers' spare capacity to control the vehicle. Comparing verbal descriptions of the roadway from experienced and novice drivers showed that experienced drivers are better able to attend to the driving environment (e.g., to perceive road signs, other vehicles, and scenery) while performing a non-driving task. This may reflect novice drivers' greater need to attend to the operational aspects of driving; more experienced drivers, having developed automaticity in performing these tasks, can better attend to the tactical demands of driving (Lansdown, 2002). Young drivers may be particularly vulnerable to distraction because their inexperience leaves them with relatively little spare capacity to attend to both the roadway and the infotainment system. However, teens may also be more expert in their use of infotainment systems and so some interaction might pose a smaller hazard than for experienced drivers.

\subsection{Failures to manage roadway and information system demands}

At the tactical level, infotainment systems can undermine driving safety by diminishing drivers' ability to anticipate roadway demands. Even with experienced drivers, cell phone use can cause marked changes in visual scanning patterns, such as reduced scanning of the mirrors, roadway, and speedometer (Recarte \& Nunes, 2000). Inexperience magnifies this tendency. One study showed that when interacting with a radio, cassette player, or cell phone, no experienced driver glanced away from the road for longer than $3 \mathrm{~s}$, but that $29 \%$ of the young drivers did so (Wikman, Nieminen, \& Summala, 1998). These young drivers also had greater variance in glances, with more short, ineffective glances. Both young and experienced drivers showed a similar decline in responsiveness to traffic signals when engaged in a simple or intense phone conversation, but young drivers responded less frequently to signals when tuning the radio (McKnight \& McKnight, 1993). It was also found that young drivers responded to fewer roadway events when dialing a hand-held phone and departed their lane more frequently when accessing voicemails, compared to more experienced drivers. Other factors making young drivers especially vulnerable to distraction may be that they are less efficient in sharing driving and non-driving demands and they do not recognize the hazards associated with infotainment interactions.

\subsection{Decision to use the infotainment system}

At the strategic level, young drivers tend to use emerging technology when driving more than experienced drivers. A focus group study examined teen drivers' willingness to interact with a wide range of infotainment systems. In these groups, young drivers were more willing than other drivers to use cell phones, text messaging, and PDAs. This study also showed that peer influence may exacerbate the tendency of young drivers to use infotainment technology while driving - passengers in the car increased the use of cell phones (Olsen, Lerner, Perel, \& Simons-Morton, 2005). A survey of 1,291 college students found that of the respondents that were drivers, $87 \%$ owned a cell phone and $86 \%$ reported using their phone at least occasionally while driving. The respondents also reported 762 crashes or near-crashes and that $21 \%$ of these incidents occurred while using a cell phone (Seo \& Torabi, 2004). Similarly, another survey found that younger drivers used a cell phone more often while driving and were more likely to experience a dangerous situation as a result of using the phone compared to experienced drivers (Poysti, Rajalin, \& Summala, 2005).

Young drivers seem more willing to use infotainment systems because they do not appreciate distracting activities. This, despite the fact that they were more likely to have crashed as a consequence of distraction (McEvoy, Stevenson, \& Woodward, 2006). Overall, young drivers may be exceptionally vulnerable to distractions because they are more likely to adopt new technology and to use it while driving. This tendency is particularly troubling given the rapid increase in potentially distracting technology that young drivers might bring into the car.

Technology can aggravate the cascade effects between levels of control. Failures at any of the levels in Fig. 2 interact in such a way that a strategic decision to engage a system on a challenging route leads to an increased burden of managing the roadway and infotainment demands at the tactical level. This makes breakdowns at the tactical level more likely and a failure to manage these distraction-induced breakdowns makes unsuccessful control at the operational level more probable. In this way, infotainment technology affects a teen passenger and may have equally tragic consequences for teen fatalities. 


\section{Advanced driver assistance systems (ADAS) to enhance young driver safety}

Although technology could distract drivers and undermine safety, it also has substantial potential to improve driving safety. Increasingly, cars are being equipped with advanced driver assistance systems (ADAS) that include GPS and navigation systems, sensor suites, and control systems that can help people drive safely. These systems may also use biometric technology to recognize individual drivers and develop a history of driving performance to assess momentary and long-term changes in the driver. Young drivers might benefit from ADAS that is developed for the general public, but greater benefits are possible by tuning this technology to the specific needs of young drivers.

Perhaps the most effective way to tune technology for teen drivers is to use it to extend proven methods for improving the safety of young drivers. Graduated driver licensing (GDL) has emerged as one of the most successful strategies to enhance the safety of young drivers (Shope \& Molnar, 2003; Williams, 2006). GDL enhances young driver safety by limiting exposure to hazards and providing a graded introduction to them. As shown in Fig. 1, another strikingly effective way to enhance young driver safety is to include an adult passenger. Adult passengers enhance safety by mitigating influence of peers and associated risky behavior and by augmenting the ability of young drivers to identify and manage hazards. A promising approach to tailoring ADAS to the needs of young drivers is to use technology to enhance GDL and to mimic the benefits of an adult passenger.

\subsection{Enhancing GDL with $A D A S$}

GDL protects young drivers from hazardous situations by limiting their exposure to young passengers, nighttime driving, alcohol, and solo driving. GDL also provides a system to gradually introduce drivers to increasingly challenging and hazardous situations. Such programs are one of the most effective ways to enhance young driver safety; however, the benefits may be limited by the blunt nature of the intervention. GDL can only limit drivers' exposure to very general hazards and cannot provide fine grained restrictions, such as helping drivers avoid particularly demanding intersections. GDL also offers only gross guidelines as to how drivers should be exposed to increasing hazards. With GDL, drivers have progressively fewer restrictions as they get older without regard for actual driving experience or expertise. The timeline of diminishing restrictions is only adjusted if drivers are caught violating traffic regulations (Ferguson, 2003). ADAS provides a much more precise means of restricting exposure to hazards and managing the introduction to increasingly challenging driving situations. Specific ways ADAS can extend GDL include:

- Allowing parents and teens to manage GDL compliance more precisely.
- Limiting exposure to specific hazards using route guidance systems that provide less hazardous routes.

- Limiting exposure to specific hazards by restricting driver speed and headway using Intelligent Speed Adaptation (ISA) and Adaptive Cruise Control; these systems can indicate speed limits, warn of speed limit violations, or limit the vehicle speed.

- Regulating the graded introduction of exposure to hazards based on driver competency as estimated by in-vehicle monitoring systems.

- Locking out certain vehicle functions, such as the radio, during early stages of independent driving.

Speed represents an especially critical hazard that current GDL programs fail to manage well. New technology offers a promising approach to help young drivers manage this hazard. Intelligent speed adaptation uses in-vehicle technology to help drivers comply with posted speed limits by alerting them when they exceed posted speeds or by limiting the speed of the vehicle to the posted speed (Rook \& Hogema, 2005). By one estimate, such a system could reduce injury crashes by $36 \%$ and fatal crashes by $59 \%$ if it were to be implemented so as to make it impossible for drivers to exceed the posted speed limit (Carsten \& Tate, 2005). Such benefits are likely to be greater for young drivers. These benefits could be even more significant if speed adaptation reflected roadway hazards such as sharp curves and weather conditions. One strategy for implementing this and other technologies as part of GDL would be to enforce hard limits on behavior during the first few months of driving and then relax the systems so as to provide only subtle reminders toward the end of the GDL period. In contrast with current GDL programs, which relax limits according to driver age, the timeline for relaxing GDL could reflect experience and expertise based on vehicle-based monitoring systems.

\subsection{Extending parental involvement with ADAS}

Adult passengers provide a substantial protective effect for young drivers. Crash rates rise dramatically when young drivers transition from driving with an adult to driving independently (Mayhew et al., 2003). The precise reasons for this protective effect are not known, but one likely reason is that young drivers avoid risky behavior while under the eye of their parents. Other reasons are that adult passengers support the young driver by pointing out hazards and by helping them accommodate the multi-tasking demands of driving. ADAS can extend some of the benefits of an adult passenger to those situations where young people drive independently. Specific examples include:

- Managing distractions to keep the driver focused on the road in hazardous situations.

- Monitoring the driver to avoid driving while fatigued, drunk or distracted. 
- Warning and possibly intervening in potential collision situations.

- Providing route guidance to relieve drivers of the burden of wayfinding.

- Providing immediate and aggregate feedback regarding driving performance.

- Identifying potential hazards.

- Providing an environment that mitigates peer influence.

One of the most pervasive problems with young drivers is a failure to recognize and manage roadway hazards. As an extension to parental involvement, in-vehicle technology could help young drivers recognize and respond to hazards. For example, sensors can detect the distance and relative speed of the vehicle ahead and provide drivers with feedback regarding their headway. One study found that such feedback dramatically reduced drivers' tendency to adopt an unsafe time headway (less than $0.8 \mathrm{~s}$ ) by approximately $25 \%$ (Shinar \& Schechtman, 2002). A similar system that provided time headway through a visual display and an auditory alert reduced the amount of time drivers spent at headways below $1 \mathrm{~s}$ (Fairclough, May, \& Carter, 1997). Yet another system that alerted drivers to excessive glances away from the road led drivers to reduce this behavior (Donmez, Boyle, \& Lee, 2006). Similar systems could alert young drivers to other types of roadway hazards, such as crosswalks and sharp curves. Alerting drivers to hazards provides an immediate benefit in that it supports a more effective response and a long-term benefit by teaching drivers about potential hazards. In this situation ADAS acts as a virtual driving instructor, helping young drivers learn about driving hazards.

Post-drive feedback regarding drivers' personal encounters with risky situations may be extremely effective. A pilot study showed that video-based feedback regarding situations that resulted in abrupt braking or steering maneuvers dramatically reduced these situations among a group of risky teen drivers (McGehee et al., 2007). Similar effects have been observed with a monitoring system that did not use video feedback (Tomer \& Lotan, 2006). Several controlled experiments have examined the effect of training drivers to detect hazards and the results show that while young drivers often fail to detect hazards, they can be trained to do so (Fisher et al., 2006; Horswill \& McKenna, 1999; Pollatsek et al., 2006). Training young drivers to anticipate risks seems to improve hazard perception rather than bring about a general reduction in risk taking (McKenna et al., 2006). These results suggest that ADAS technology that records drivers' lapses in detecting hazards and then supports a subsequent review with the parents might be a particularly effective way to help young drivers detect hazards and reduce risk taking behavior.

Post-drive feedback provides other benefits as well. Such systems would help parents understand how challenging driving can be for a young driver and set the context for a meaningful discussion of those challenges (Simons-Morton
\& Hartos, 2003). This benefit stresses the need to think beyond the vehicle when tailoring technology to teen drivers. Properly implemented, ADAS technology can support a collaboration between parents and teens in developing safe driving habits, even when teens drive independently. More generally, extending parental involvement into the car when the parent is absent could substantially mitigate peer pressure to engage in risky behaviors. Because such a system would "bring the parent into the car" only when a lapse occurs, it would provide a natural graduation from close supervision to independent driving.

\subsection{Caveats regarding $A D A S$}

Although technology often appears quite promising, it often fails to deliver expected benefits (Tenner, 1996). As an example, poor understanding of antilock brake systems (ABS) undermined their potential benefit (Mollenhauer, Dingus, Carney, Hankey, \& Jahns, 1997). More importantly, drivers often adapt their driving to capitalize on the capability of ABS. Taxi drivers with ABS adopted shorter time headways compared to taxis without ABS (Sagberg, Fosser, \& Saetermo, 1997). Evans (2004) reviewed several studies that showed that rollover risk increased from $14 \%$ to $94 \%$ for vehicles equipped with ABS. It is therefore possible that intelligent speed adaptation systems might lead drivers to become overly reliant on the system, and fail to adopt slower speeds when road conditions deteriorate (Lee \& See, 2004). More generally, vehicle automation, such as ACC, can distance people from the task of driving and diminish their awareness of the roadway (Stanton \& Young, 2005; Walker, Stanton, \& Young, 2006). Automation often masks real complexity with apparent simplicity (Woods, 1994), which may be particularly insidious for young drivers because vehicle automation may amplify overconfidence in driving ability. The design of any safety intervention must consider the tendency of drivers to adapt (Stetzer \& Hofmann, 1996; Wilde, 1988).

A systematic introduction of new vehicle technology that enhances currently successful interventions - GDL and supervised driving - make unanticipated negative effects less likely than a piecemeal introduction of uncoordinated systems. However, ADAS technology that intends to enhance safety might have the inadvertent consequence of inviting a virtual teen passenger into the vehicle. Specifically, a collision warning system, designed to enhance hazard awareness and promote more conservative driving, might inadvertently bring peer influences into the car and lead a young driver to maximize rather than minimize the degree and number of warnings received. This example stresses the need to consider technology as a virtual adult driver that is brought into the car according to the needs of the young driver.

Beyond the potential for drivers to adapt in unforeseen ways and erode potential safety benefits, technology cannot produce benefits if young drivers fail to accept it. 
Unfortunately, young drivers are less likely to accept restrictions on the use of cell phones relative to experienced drivers (Lamble, Rajalin, \& Summala, 2002). Results from a focus group of drivers 17-25 years old suggest that relatively unobtrusive technology such as seat belt reminders and alcohol interlocks were most acceptable. More intrusive technology, such as fatigue monitoring, collision warning devices, and intelligent speed adaptation were less acceptable (Young, Regan, \& Mitsopoulos, 2004). It may be that the most effective technology may also be the least acceptable and so a substantial effort must be made to include the perspective of teens in the design, along with an effort to shape teen culture to accept constraints on driving that improve safety (Moeckli \& Lee, 2007). Teens may be more likely to accept technology if they see it as a mentor rather than as a monitor.

\section{Conclusion}

Rapidly evolving technology has enormous potential to affect driving safety - both positively and negatively. The factors that cause young drivers to crash more frequently than other drivers amplify the positive and negative potential of new technology. Young drivers are particularly vulnerable to distractions posed by infotainment systems, but could benefit tremendously from driver support systems. Extending proven approaches to enhance teen driving — GDL and supervised driving — represents the most promising path for implementing new technology. Tailoring technology to teen drivers can have the effect of placing an adult passenger in the teen's vehicle. Conversely, a failure to manage technology may have the inadvertent and disastrous effect of inviting several young male passengers into the teen's car.

The analogy of a technology as a passenger, either a teen or an adult, may seem strained. However, numerous studies show that people often respond to technology as they might respond to a person (Nass \& Brave, 2005; Nass et al., 2005; Reeves \& Nass, 1996). More generally, technology often engages emotional and social responses that have powerful effects that often go unappreciated (Lee, 2006; Lee \& See, 2004; Norman, 2004). Although imperfect, the analogy of technology as a teen or as an adult passenger can help designers and policy makers address the complex challenges of tailoring technology to teen drivers.

A failure to manage technology may cause young drivers to face a "perfect storm" of emerging technologies. The coming years will bring increasingly complex distractions, increasingly complex vehicles, and increasingly confident, but unprepared drivers. This combination has the potential to undermine teen driving safety to a greater extent than any one of these trends alone. Fortunately, technology also has the potential to enhance the safety of young drivers. There is an urgent need for researchers, designers, and policy makers to consider how to avoid this "perfect storm" and capitalize on the potential benefits of emerging technology.

\section{Acknowledgements}

This manuscript was greatly improved by the comments of many people at the National Safety Council's Teen Driving Symposium Dan McGehee, Mireille Raby, Monica Lees, and Josh Hoffman. In addition, Teresa Lopes at the University of Iowa Public Policy Center aided with technical editing.

\section{References}

Allen, T. M., Lunenfeld, H., \& Alexander, G. J. (1971). Driver information needs. Highway Research Board, 366, 102-115.

Alm, H., \& Nilsson, L. (1994). Changes in driver behaviour as a function of handsfree mobile phones: A simulator study. Accident Analysis and Prevention, 26(4), 441-451.

Alm, H., \& Nilsson, L. (1995). The effects of a mobile telephone task on driver behavior in a car following situation. Accident Analysis and Prevention, 27(5), 707-715.

Brown, I. D., \& Groeger, J. A. (1988). Risk perception and decision taking during the transition between novice and experienced driver status. Ergonomics, 31(4), 585-597.

Brown, I. D., Tickner, A. H., \& Simmonds, D. C. V. (1969). Interference between concurrent tasks of driving and telephoning. Journal of Applied Psychology, 53(5), 419-424.

Carsten, O. M. J., \& Tate, E. (2005). Intelligent speed adaptation: accident savings and cost-benefit analysis. Accident Analysis and Prevention, 37 (3), 407-416.

Chen, L., Baker, S. P., Braver, E. R., \& Li, G. (2000). Carrying passengers as a risk factor for crashes fatal to 16- and 17-year old drivers. Journal of the American Medical Association, 283(12), 1578-1582.

Cohen, J. T., \& Graham, J. D. (2003). A revised economic analysis of restrictions on the use of cell phones while driving. Risk Analysis, 23(1), 1-14.

Crundall, D. E., \& Underwood, G. (1998). Effects of experience and processing demands on visual information acquisition in drivers. Ergonomics, 41(4), 448-458.

Dingus, T. A., Hulse, M. C., Mollenhauer, M. A., Fleischman, R. N., McGehee, D. V., \& Manakkal, N. (1997). Effects of age, system experience, and navigation technique on driving with an advanced traveler information system. Human Factors, 39(2), 177-199.

Donmez, B., Boyle, L. N., \& Lee, J. D. (2006). The impact of distraction mitigation strategies on driving performance. Human Factors, 48(4), 785-804.

Evans, L. (2004). Traffic safety. Bloomfield Hills, MI: Science Serving Society.

Evans, L., \& Wasielewski, P. (1983). Risky driving related to driver and vehicle characteristics. Accident Analysis and Prevention, 15(2), 121-136.

Fairclough, S. H., May, A. J., \& Carter, C. (1997). The effect of time headway feedback on following behaviour. Accident Analysis and Prevention, 29(3), 387-397.

Ferguson, S. A. (2003). Other high-risk factors for young drivers - how graduated licensing does, doesn't, or could address them. Journal of Safety Research, 34(1), 71-77.

Fisher, D. L., Laurie, N. E., Glaser, R., Connerney, K., Pollatsek, A., Duffy, S. A., et al. (2002). Use of a fixed-base driving simulator to evaluate the effects of experience and PC-based risk awareness training on drivers' decisions. Human Factors, 44(2), 287-302.

Fisher, D. L., Pollatsek, A. P., \& Pradhan, A. (2006). Can novice drivers be trained to scan for information that will reduce their likelihood of a crash? Injury Prevention, 12, 25-29.

Glassbrenner, D. (2005). Driver Cell Phone use in 2004-Overall Results (No. DOT HS 809 847). Washington, DC: U.S. Department of Transportation.

Horrey, W. J., \& Wickens, C. D. (2006). Examining the impact of cell phone conversations on driving using meta-analytic techniques. Human Factors, 48(1), 196-205. 
Horswill, M. S., \& McKenna, F. P. (1999). The development, validation, and application of a video-based technique for measuring an everyday risktaking behavior: Drivers' speed choice. Journal of Applied Psychology, 84(6), 977-985.

Horswill, M. S., Waylen, A. E., \& Tofield, M. I. (2004). Drivers' Ratings of Different Components of Their Own Driving Skill: A Greater Illusion of Superiority for Skills That Relate to Accident Involvement. Journal of Applied Social Psychology, 34(1), 177-195.

Ivancic, K., \& Hesketh, B. (2000). Learning from errors in a driving simulation: effects on driving skill and self-confidence. Ergonomics, 43 (12), 1966-1984

Jonah, B. A. (1990). Age differences in risky driving. Health Education Research, 5(2), 139-149.

Kahneman, D. (1973). Attention and effort. Englewood Cliffs: Prentice-Hall.

Laapotti, S., Keskinen, E., Hatakka, M., \& Katila, A. (2001). Novice drivers' accidents and violations - a failure on higher or lower hierarchical levels of driving behaviour. Accident Analysis and Prevention, 33(6), 759-769

Lamble, D., Laakso, M., \& Summala, H. (1999). Detection thresholds in car following situations and peripheral vision: implications for positioning of visually demanding in- car displays. Ergonomics, 42(6), 807-815.

Lamble, D., Rajalin, S., \& Summala, H. (2002). Mobile phone use while driving: public opinions on restrictions. Transportation, 29(3), 223-236.

Lansdown, T. C. (2002). Individual differences during driver secondary task performance: verbal protocol and visual allocation findings. Accident Analysis and Prevention, 34(5), 655-662.

Lee, J. D. (2006). Affect, attention, and automation. In A. Kramer, D. Wiegmann, \& A. Kirlik (Eds.), Attention: From theory to practice. New York: Oxford University Press.

Lee, J. D., \& See, K. A. (2004). Trust in technology: Designing for appropriate reliance. Human Factors, 46(1), 50-80.

Lee, J. D., \& Strayer, D. L. (2004). Preface to a special section on driver distraction. Human Factors, 46, 583-586.

Lin, M. L., \& Fearn, K. T. (2003). The provisional license: nighttime and passenger restrictions - a literature review. Journal of Safety Research, 34(1), 51-61.

Matthews, M. L., \& Moran, A. R. (1986). Age differences in male drivers' perception of accident risk: The role of perceived driving ability. Accident Analysis and Prevention, 18(4), 299-313.

Mayhew, D. R., Simpson, H. M., \& Pak, A. (2003). Changes in collision rates among novice drivers during the first months of driving. Accident Analysis and Prevention, 35, 683-691.

McCartt, A. T., Hellinga, L. A., \& Bratiman, K. A. (2006). Cell phones and driving: Review of research. Traffic Injury Prevention, 7, 89-106.

McCartt, A. T., Shabanova, V. I., \& Leaf, W. A. (2003). Driving experience, crashes and traffic citations of teenage beginning drivers. Accident Analysis and Prevention, 35(3), 311-320.

McEvoy, S. P., Stevenson, M. R., \& Woodward, M. (2006). The impact of driver distraction on road safety: results from a representative survey in two Australian states. Injury Prevention, 12(4), 242-247.

McGehee, D. V., Carney, C., Raby, M., Reyes, M. L., \& Lee, J. D. (2007). Extending parental mentoring using an event-triggered video intervention in rural teen drivers. Journal of Safety Research, 38(2).

McGwin, G., \& Brown, D. B. (1999). Characteristics of traffic crashes among young, middle-aged, and older drivers. Accident Analysis and Prevention, 31(3), 181-198.

McKenna, F. P., Horswill, M. S., \& Alexander, J. L. (2006). Does anticipation training affect drivers' risk taking? Journal of Experimental Psychology. Applied, 12(1), 1-10.

McKnight, A. J., \& McKnight, A. S. (1993). The Effect of Cellular Phone Use Upon Driver Attention. Accident Analysis and Prevention, 25(3), 259-265.

McKnight, A. J., \& McKnight, A. S. (2003). Young novice drivers: careless or clueless? Accident Analysis and Prevention, 35(6), 921-925.

Michon, J. A. (1985). A critical view of driver behavior models: What do we know, what should we do? In L. Evans \& R.C. Schwing (Eds.), Human behavior and traffic safety (pp. 485-520). New York: Plenum Press.
Moeckli, J., \& Lee, J. D. (March 28 2007). The making of driving cultures Retrieved.

Mollenhauer, M. A., Dingus, T. A., Carney, C., Hankey, J. M., \& Jahns, S. (1997). Anti-lock brake systems: An assessment of training on driver effectiveness. Accident Analysis and Prevention, 29(1), 97-108.

Mourant, R. R., \& Rockwell, T. H. (1972). Strategies of visual search by novice and experienced drivers. Human Factors, 14(4), 325-335.

Nass, C., \& Brave, S. (2005). Wired for speech : How voice activates and advances the human-computer relationship. Cambridge, MA: MIT Press.

Nass, C., Jonsson, I. M., Harris, H., Reaves, B., Endo, J., Brave, S., et al. (2005). Improving automotive safety by pairing driver emotion and care voice emotion. Conference on human factors in computing systems (pp. 1973-1976)

Norman, D. A. (2004). Emotional design. New York: Basic Books.

Olsen, E. C. B., Lerner, N., Perel, M., \& Simons-Morton, B. G. (2005). Incar electronic device use amoung teen drivers. Transportation research board annual meeting.

Patten, C. J. D., Kircher, A., Ostlund, J., Nilsson, L., \& Svenson, O. (2006). Driver experience and cognitive workload in different traffic environments. Accident Analysis and Prevention, 38(5), 887-894.

Pollatsek, A., Fisher, D. L., \& Pradhan, A. (2006). Identifying and remedying failures of selective attention in younger drivers. Current Directions in Psychological Science, 15(5), 255-259.

Poysti, L., Rajalin, S., \& Summala, H. (2005). Factors influencing the use of cellular (mobile) phone during driving and hazards while using it. Accident Analysis and Prevention, 37(1), 47-51.

Ranney, T. A. (1994). Models of driving behavior: A review of their evolution. Accident Analysis and Prevention, 26(6), 733-750.

Recarte, M. A., \& Nunes, L. M. (2000). Effects of verbal and spatialimagery tasks on eye fixations while driving. Journal of Experimental Psychology. Applied, 6(1), 31-43.

Reeves, B., \& Nass, C. (1996). The media equation: How people treat computers, television, and new media like real people and places. New York: Cambridge University Press.

Regan, M. A., Lee, J. D., \& Young, K. L. (In preparation). Driver distraction: Theory, effects and mitigation. CRC Press.

Rook, A. M., \& Hogema, J. H. (2005). Effects of human-machine interface design for intelligent speed adaptation on driving behavior and acceptance. Human performance; simulation and visualization (pp. 79-86).

Sagberg, F., Fosser, S., \& Saetermo, I. A. F. (1997). An investigation of behavioural adaptation to airbags and antilock brakes among taxi drivers. Accident Analysis and Prevention, 29(3), 293-302.

Senders, J. W., Kristofferson, A. B., Levison, W. H., Dietrich, C. W., \& Ward, J. L. (1967). The attentional demand of automobile driving. Highway Research Record, 195, 15-33.

Seo, D. C., \& Torabi, M. R. (2004). The impact of in-vehicle cell-phone use on accidents or near-accidents among college students. Journal of American College Health, 53(3), 101-107.

Shinar, D., Meir, M., \& Ben-Shoham, I. (1998). How automatic is manual gear shifting? Human Factors, 40(4), 647-654.

Shinar, D., \& Schechtman, E. (2002). Headway feedback improves intervehicular distance: A field study. Human Factors, 44(3), 474-481.

Shope, J. T., \& Molnar, L. J. (2003). Graduated driver licensing in the United States: evaluation results from the early programs. Journal of Safety Research, 34(1), 63-69.

Simons-Morton, B. G., \& Hartos, J. L. (2003). How well do parents manage young driver crash risks? Journal of Safety Research, 34(1), 91-97.

Simons-Morton, B. G., Lerner, N., \& Singer, J. (2005). The observed effects of teenage passengers on risky driving behavior of teenage drivers. Accident Analysis and Prevention, 37, 973-982.

Smiley, A., Smahel, T., \& Eizenman, M. (2004). Impact of video advertising on driver fixation patterns. Driver and vehicle simulation, human performance, and information systems for highways; railroad safety; and visualization in transportation (pp. 76-83).

Stanton, N., \& Young, M. S. (2005). Driver behaviour with adaptive cruise control. Ergonomics, 48(10), 1294-1313. 
Stetzer, A., \& Hofmann, D. A. (1996). Risk compensation: Implications for safety interventions. Organizational Behavior and Human Decision Processes, 66(1), 73-88.

Stutts, J. C., Reinfurt, D. W., Staplin, L., \& Rodgman, E. A. (2001). The role of driver distraction in traffic crashes: AAA foundation of traffic safety.

Subramanian, R. (2005). Motor vehicle traffic crashes as a leading cause of death in the United States, 2002 (No. DOT HS 809 831). Washington, DC: U.S. Department of Transportation.

Summala, H. (1996). Accident risk and driver behaviour. Safety Science, 22 (1-3), 103-117.

Sussman, E. D., Bishop, H., Madnick, B., \& Walter, R. (1985). Driver inattention and highway safety. Transportation Research Record, 1047, 40-48.

Svenson, O. (1981). Are we all less risky and more skillful than our fellow drivers? Acta Psychologica, 47, 143-148.

Telstra. (2003). Telstra, Police and NRMA Insurance join forces to target mobile phone use on Australian roads. Telstra news release. www. telstra.com.au/newsroom

Tenner, E. (1996). Why things bite back: Technology and the revenge of unanticipated consequences. New York: Knopf.

Tomer, T., \& Lotan, T. (2006). In-vehicle data recorder for evaluation of driving behavior and safety. Transportation Research Record, 1953, 112-119.

Underwood, G., Chapman, P., Brocklehurst, N., Underwood, J., \& Crundall, D. (2003). Visual attention while driving: sequences of eye fixations made by experienced and novice drivers. Ergonomics, 46(6), 629-646.

Underwood, G., Crundall, D., \& Chapman, P. (2002). Selective searching while driving: the role of experience in hazard detection and general surveillance. Ergonomics, 45(1), 1-12.

Vollrath, M., Meilinger, T., \& Kruger, H. P. (2002). How the presence of passengers influences the risk of a collision with another vehicle. $A c$ cident Analysis and Prevention, 34(5), 649-654.

Walker, G. H., Stanton, N., \& Young, M. S. (2006). The ironies of vehicle feedback in car design. Ergonomics, 49(2), 161-179.

Wang, J., Knipling, R. R., \& Goodman, M. J. (1996). The role of driver inattention in crashes; new statistics from the 1995 crashworthiness data system (CDS). 40th annual proceedings: Association for the advancement of automotive medicine (pp. 377-392).

Wikman, A. S., Nieminen, T., \& Summala, H. (1998). Driving experience and time-sharing during in-car tasks on roads of different width. Ergonomics, 41(3), 358-372.

Wilde, G. J. S. (1988). Risk homeostasis theory and traffic accidents: Propositions, deductions and discussion of dissension in recent reactions. Ergonomics, 31(4), 441-468.

Williams, A. F. (2003). Teenage drivers: patterns of risk. Journal of Safety Research, 34(1), 5-15.

Williams, A. F. (2006). Young driver risk factors: successful and unsuccessful approaches for dealing with them and an agenda for the future. Injury Prevention, 12, 4-8.

Woods, D. D. (1994). Automation: Apparent simplicity, real complexity. In M. Mouloua \& R. Parasuraman (Eds.), Human performance in automated systems: Current research and trends (pp. 1-7). Hillsdale, NJ: Lawrence Erlbaum Associates.

Young, K. L., Regan, M. A., \& Mitsopoulos, E. (2004). Acceptability to young drivers of in-vehicle intelligent transport systems. Road Transportation Research, 13(2), 6-16.

John D. Lee received a B.A. in psychology and a B.S. in mechanical engineering from Lehigh University, Bethlehem, PA, in 1987 and 1988, respectively, and a M.S. in industrial engineering and a Ph.D. in mechanical engineering from the University of Illinois at Urbana-Champaign, in 1989 and 1992, respectively. He is currently a Professor in the Department of Mechanical and Industrial Engineering, affiliated with the National Advanced Driving Simulator, and the Director of the Cognitive Systems Laboratory at the University of Iowa, Iowa City, IA. His research enhances the safety and acceptance of complex human-machine systems by considering how technology mediates attention. 